\title{
E-Marketplace dengan Metode Upselling Study Kasus Toko Bento Sport Berbasis Web
}

\author{
Fajar Diski Saputro, Dwi Tjahjo Seabtian \\ Fakultas Ilmu Komputer, Sistem Informasi, Universitas Darwan Ali, Sampit, Indonesia \\ Email: ${ }^{1}$ fasensei11@gmail.com, ${ }^{2}$ dwiraked17@gmail.com
}

\begin{abstract}
Abstrak-Toko online atau E-commerce merupakan bisnis online yang sedang berkembang pesat saat ini. Pembeli dapat menghemat waktu dan tenaga dengan belanja online melalui e-commerce. Dengan bantuan e-commerce, penjualan tidak dibatasi oleh tempat dan mengurus secara global. padatopik kali ini BENTO SPORT adalah toko yang bergerak di bidang alat dan keperluan olah raga. Dalam penjualan banyak pembeli yang kesulitan membeli produk di Toko BENTO SPORT. Dari pertanyaan tersebut maka dibuatlah solusi aplikasi penjualan berbasis website online. Dengan adanya aplikasi penjualan online maka pembeli tidak harus datang kembali dan juga tidak dibatasi oleh tempat dan waktu.
\end{abstract}

Kata Kunci: Up-Selling; e-Marketplace; Pengujian Black-Box; Online; Pemesanan Produk

Abstract-Online store or E-commerce is an online business that is growing rapidly at this time. Shoppers can save time and effort by shopping online through e-commerce. With the help of e-commerce, sales are not limited by place and are managed globally. in this topic, BENTO SPORT is a shop that specializes in sports equipment and supplies. In sales, many buyers have difficulty buying products at the BENTO SPORT Shop. From these questions, an online website-based sales application solution was made. With an online sales application, buyers do not have to come back and are not limited by place and time.

Keywords: Up-Selling; e-Marketplace; Black-Box Test; Online; Product Ordering

\section{PENDAHULUAN}

Bento sport adalah toko yang bergerak dalam bidang penjualan produk-produk yang berhubungan dengan olahlaraga, seperti baju, sepatu, dan peralatan olah raga lainnya. Bento Sport ini berdiri di lokasi yang kurang strategis, sehingga tidak banyak orang yang tahu akan keberadaan toko olahraga ini. Bento Sport juga tidak memiliki wadah atau tempat untuk memasarkan dan mempromosikan produk yang dijual pada tokonya. Kurangnya strategi penjualan produk olahraga kepada customer juga menjadi kendala untuk toko Bento Sport, sehingga para customer yang datang ke toko Bento Sport terkadang kebingungan untuk memilih produk yang cocok dengan kualitas bagus, dan produk apa yang paling banyak diminati oleh customer lainnya. Sehingga Toko Bento Sport memilik omset yang kurang stabil dari proses penjualan barang-barangnya.

Permasalahan yang dihadapi pada Toko Bento Sport sekarang ini adalah, pemantauan ketersediaan stock produk olahraga pada toko Bento Sport terkadang juga menjadi kendala tersendiri bagi pemilik, hal itu disebabkan karena pemantauan ketersediaan stock produk dilakukan dengan cara memprediksi sehingga pemilik tidak dapat mengetahui dengan pasti produk apa yang stocknya sisa sedikit dan produk apa yang stocknya masih tersisa banyak. Pemilik toko juga kesulitan memantau perkembangan dari usahanya, karena pemilik toko tidak memiliki catatan apapun tentang hasil dari penjualannya produk pada tokonya.

Untuk mengatasi permasalahan yang ada maka solusi yang diberikan adalah membuat E-Marketplace dengan metode Up-Selling diterapkan pada toko Bento Sport, solusi ini dapat menjadi alternatif yang sangat baik untuk mengatasi permasalahan yang ada.

Tujuan dari penelitian ini adalah untuk mengatasi permasalahan yang ada, E-marketplace ini juga dapat menjadi sarana untuk memasarakan dan merekomendasikan produk yang di jual pada Bento Sport dan solusi untuk perkenalkan toko ini pada calon customer, pemilik dapat dengan mudah memantau ketersediaan stock produk dan mengontrol stock produk, pemilik toko juga dapat dengan mudah memantau perkembangan usahanya melalui produk apa saja yang paling banyak terjual dan paling diminati oleh customer.

\section{METODOLOGI PENELITIAN}

Diperlukan adanya tempat objek penelitian untuk mengetahui keakuratan data dengan sistematis, proses dilakukan agar data yang diperoleh dapat terintegrasi menjadi suatu bagian yang komplek dan dapat dipertanggungjawabkan kebenaran nya. Di dalam penelitian ini data dapat di peroleh dari sumber sumber berikut:

\subsection{Metode Pengumpulan data}

Pengumpulan data merupakan salah satu tahapan sangat penting dalam penelitian. Teknik pengumpulan data yang benar akan menghasilkan data yang memiliki kredibilitas tinggi, dan sebaliknya. Adapun teknik pencarian data data sebagai berikut[1]:

a) Metode Observasi 


\section{Journal of Computer System and Informatics (JoSYC)}

Volume 2, No. 4, August 2021, Page 316-320

ISSN 2714-8912 (media online)

ISSN 2714-7150 (media cetak)

DOI 10.47065/josyc.v2i4.849

Penelitian langsung turun kelapangan untuk mengidentifikasi secara langsung untuk mengambil data yang diperlukan dalam guna perancangan membangun aplikasi. Dari hasil pengamatan tersebut lokasi dari Bento Sport ini kurang strategis, pengunjung yang tidak terlalu banyak yang datang ke toko.

b) Metode Wawancara

Kegiatan wawancara dilakukan untuk mendapatkan informasi yang mendalam tentang persepsi, pandangan, wawasan, atau aspek kepribadian para peserta didik yang diberikan secara lesan dan spontan. Kegiatan wawancara agar lebih terarah, biasanya dilengkapi dengan pembuatan pedoman wawancara.Wawancara yang baik adalah yang bersifat mendalam. Artinya dengan menginterpretasi jawaban siswa akan diperoleh banyak informasi, yang mungkin tidak bisa ditemukan pada penggunaan metode lainnya.

c) Studi Literatur

Studi Literatur untuk memperoleh informasi dalam perancangan dan pembuatan sistem informasi EMarketplace, untuk usaha penjualan produk olahraga pada Bento Sport yang berpedoman buku-buku yang berhubungan dengan E-Marketplace. Metodologi ini dilakukan dengan cara membaca dan mempelajari bukubuku yang berhubungan dengan rancang bangun sistem, pemrograman web serta buku-buku yang mendukung topik yang akan dibahas dalam penyusunan penelitian ini.

\subsection{Metode Pengembangan Program}

Pada penelitian ini metode pengembangan system yang cocok pada pembangunan program ini adalah metode waterfall. Berikut adalah tahapan pengembangan system menggunakan metode waterfall:

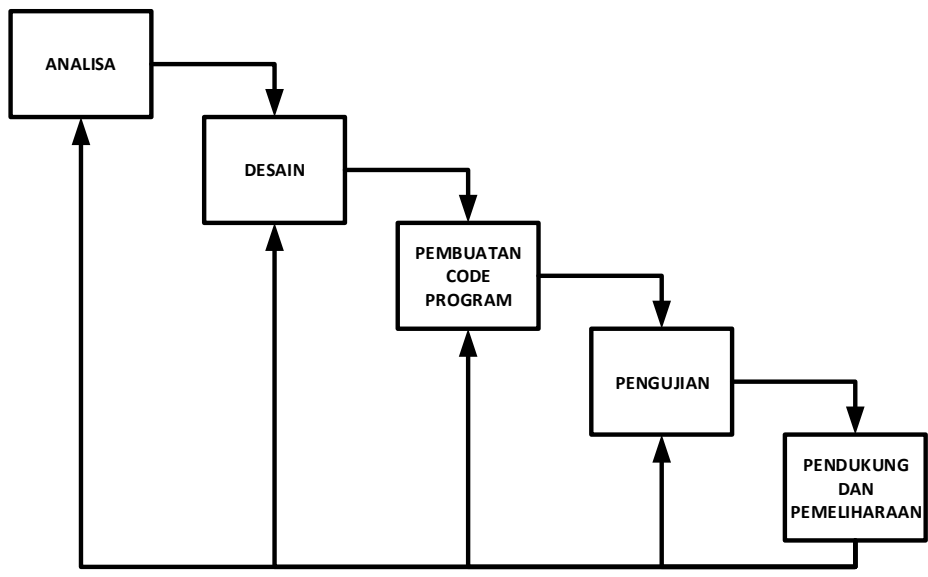

a) Analisa Kebutuhan System

Gambar 1. Tahapan Pengembangan Sistem

Pada tahap ini penulis menganalisa apa saja kebutuhan yang akan dimuat kedalam system mulai dari isi database, aplikasi yang digunakan, dan kebutuhan content pada halaman website. Untuk semua kebutuhan system itu didapat dari data hasil wawancara dengan pemilik usaha sebelumnya.

b) Desain

Setelah semua kebutuhan untuk system dirasa sudah terpenuhi, selanjutnya masuk pada tahapan desain, pada tahap desain penulis membuat rancangan tampilan untuk website, dan website dirancang agar mudah digunakan untuk user.

c) Pembuatan Code Program

Setelah desain sudah dinyatakan clear, selanjutnya masuk kedalam tahap pembuatan code program yang olah dengan menggunakan aplikas dreamwaever dan aplikasi pendukung lainnya.

d) Pengujian

Pada tahap pengujian, aplikasi yang sudah selasai dikerjakan kemudian diujikan untuk digunakan oleh user, yaitu pemilik toko dan customer. Pengujian dilakukan menggunakan Black-Box Testing merupakan teknik pengujian perangkat lunak yang berfokus pada spesifikasi fungsional dari perangkat lunak. Black-Box Testing memungkinkan pengembang software untuk membuat himpunan kondisi input yang akan melatih seluruh syarat-syarat fungsional suatu program. Keuntungan penggunaan metode black-box tetsting adalah: 1). Penguji tidak perlu memiliki pengetahuan tentang bahasa pemrograman tertentu; 2). Pengujian dilakukan dari sudut pandang pengguna, ini membantu untuk mengungkapkan ambiguitas atau inkonsistensi dalam spesifikasi persyaratan; 3). Programmer dan tester keduanya saling bergantung satu sama lain. Kekurangan dari metode black-box testing adalah: 1). Uji kasus sulit disain tanpa spesifikasi yang jelas; 2). Kemungkinan memiliki pengulangan tes yang sudah dilakukan oleh programmer; 3). Beberapa bagian back end tidak diuji sama sekali [2]-[5].

e) Pendukung atau Pemeliharaan 
Journal of Computer System and Informatics (JoSYC)

Volume 2, No. 4, August 2021, Page 316-320

ISSN 2714-8912 (media online)

ISSN 2714-7150 (media cetak)

DOI 10.47065/josyc.v2i4.849

Pada tahap ini penulis selalu memantau aplikasi yang telah diujikan apakah ada munculnya kendala dari aplikasi, seperti bug, error, dan keinginan pemilik untuk penambahan fitur, sehingga muncul kenyamanan dalam penggunan aplikasi dari pihak user.

\section{HASIL DAN PEMBAHASAN}

\subsection{Rancangan Sistem}

Pada bagian ini berisi analisa, hasil serta pembahasan dari topik penelitian, yang bisa di buat terlebih dahulu metodologi penelitian. Bagian ini juga merepresentasikan penjelasan yang berupa penjelasan, gambar, tabel dan lainnya. Berikut rancangan desain sistem yang diusulkan berupa flowmap. Rancangan Sistem Dalam Bentuk DFD (Data Flow Diagram).

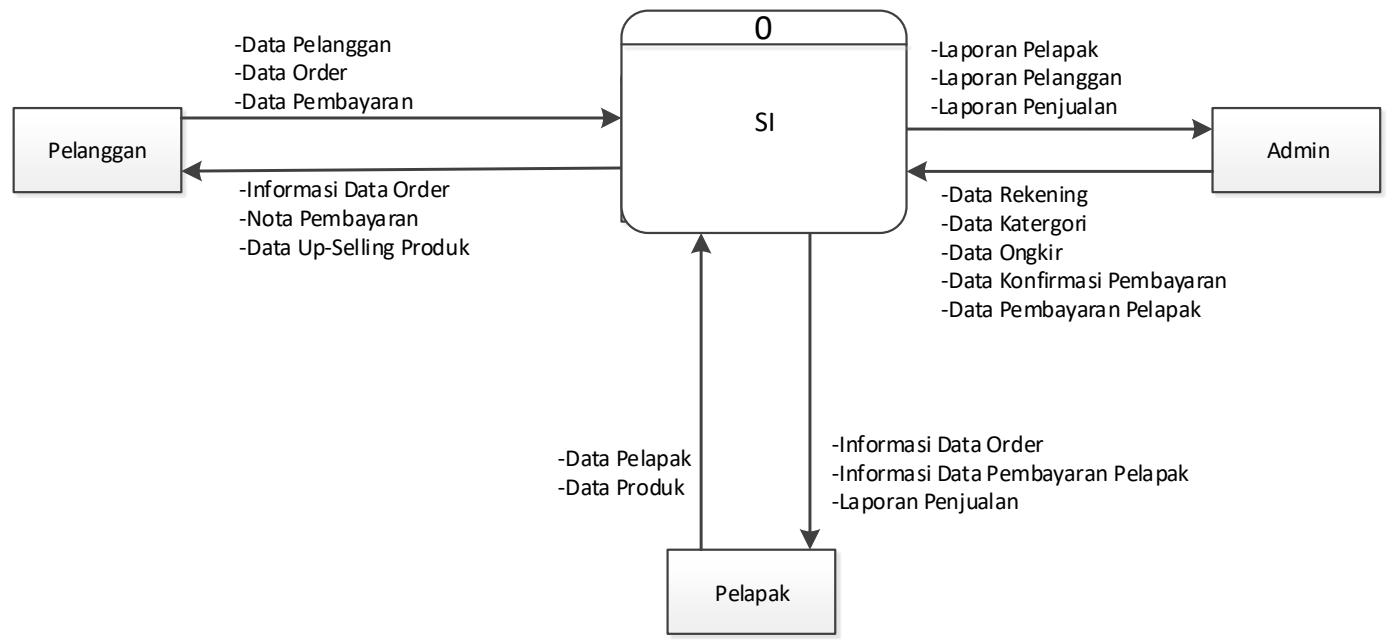

Gambar 2. Konteks Diagram

\subsection{Implementasi Program}

Pada bagian ini akan dibahas mengenai tampilan aplikasi dari Toko Bento Sport.

\section{a. Halaman Utama}

Berikut tampilan ketika pertama kali masuk mengakses sistem dimana setiap orang bisa bebas melihat produk yang tersedia namun ketika ingin mengorder maka akan diminta untuk login terlebih dahulu atau buat akun bagi yang belum punya. Dibagian kiri tampilan terdafat form login yang bisa digunakan langsung oleh admin, pelapak, serta pembelibentuk DFD (Data flow Diagram)

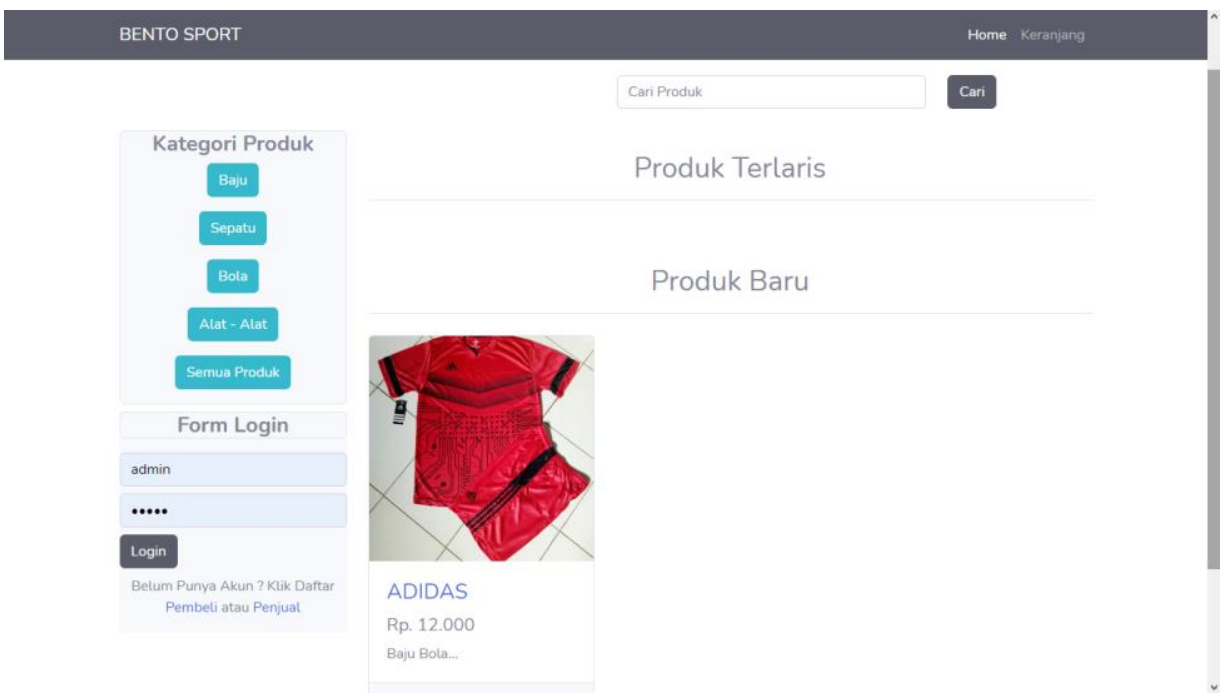

Gambar 3. Halaman utama

\section{b. Input produk}

Halaman input produk diakses oleh pelapak untuk memasukan data produk yang akan dijual dengan mengisi form tambah produk yang didalamnya ada nama produk, pilih kategori produk, deskripsi produk, mengisi, 
Journal of Computer System and Informatics (JoSYC)

Volume 2, No. 4, August 2021, Page 316-320

ISSN 2714-8912 (media online)

ISSN 2714-7150 (media cetak)

DOI 10.47065/josyc.v2i4.849

harga produk, jumlah stok, berat produk, dan memasukan gambar produk kemudian menekan tombol simpan untuk menyimpan data produk.

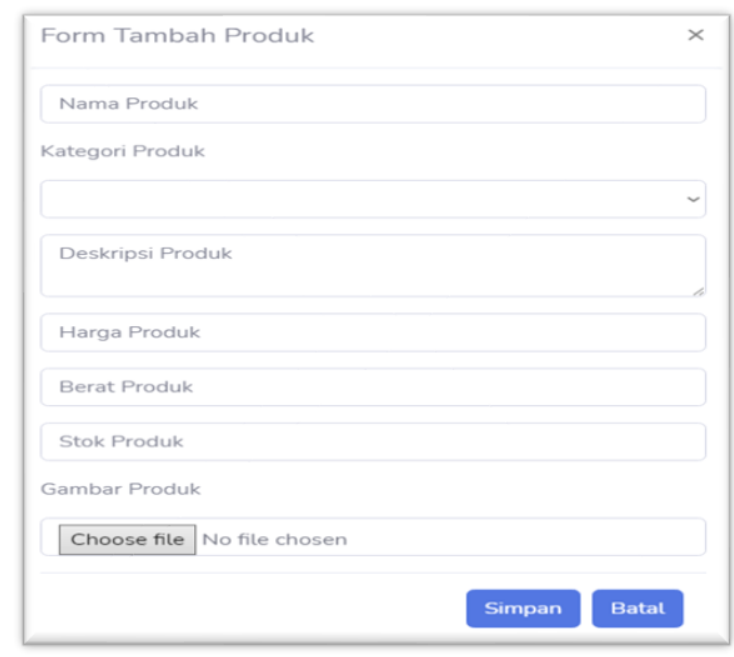

Gambar 4. Tampilan Input Produk Baru

\subsection{Hasil Uji Black-Box Testing}

Hasil dari pengujian program aplikasi yang telah berjalan, dan dapat disimpulkan program yang telah berjalan dapat berjalan dengan normal dan sesuai dengan apa yang diharapkan: Berikut adalah hasil dari pengujian program:

Tabel 1. Pengujian Aplikasi

\begin{tabular}{|c|c|c|c|c|c|}
\hline No & $\begin{array}{l}\text { Skenario } \\
\text { Pengujian }\end{array}$ & Kasus Pengujian & $\begin{array}{l}\text { Hasil Yang } \\
\text { Diharapkan }\end{array}$ & $\begin{array}{c}\text { Hasil } \\
\text { Pengujian }\end{array}$ & Kesimpulan \\
\hline 1 & Login User & $\begin{array}{l}\text { Login User dengan } \\
\text { akun yang belum } \\
\text { didaftarkan }\end{array}$ & $\begin{array}{l}\text { Tidak dapat login dan diminta } \\
\text { untuk daftar }\end{array}$ & Sesuai & Berhasil \\
\hline 2 & $\begin{array}{l}\text { Lihat detail } \\
\text { barang (belum } \\
\text { Login User) }\end{array}$ & $\begin{array}{l}\text { User klik tombol } \\
\text { 'Detail' pada setiap } \\
\text { barang yang muncul } \\
\text { di halaman utama }\end{array}$ & $\begin{array}{l}\text { User dapat mengetahui detail } \\
\text { barang walau belum Login User }\end{array}$ & Sesuai & Berhasil \\
\hline 3 & $\begin{array}{l}\text { Akses } \\
\text { Keranjang } \\
\text { (belum Login } \\
\text { User) }\end{array}$ & $\begin{array}{l}\text { User klik } \\
\text { 'Keranjang' pada } \\
\text { halaman utama }\end{array}$ & $\begin{array}{l}\text { User diminta login telebih dahulu } \\
\text { menggunakan akun yang terdaftar } \\
\text { sebagai pembeli }\end{array}$ & Sesuai & Berhasil \\
\hline 4 & Kategori & $\begin{array}{l}\text { User klik tombol } \\
\text { 'Kategori' dan } \\
\text { barang diurutkan } \\
\text { sesuai kategorinya }\end{array}$ & $\begin{array}{l}\text { Barang di Halaman Utama } \\
\text { berubah dan diurutkan } \\
\text { berdasarkan Ketegori yang dipilih }\end{array}$ & Sesuai & Berhasil \\
\hline 5 & $\begin{array}{l}\text { Daftar User } \\
\text { baru }\end{array}$ & $\begin{array}{l}\text { Klik pada daftar } \\
\text { sebagai Pembeli } \\
\text { atau Penjual }\end{array}$ & $\begin{array}{l}\text { Form yang akan disediakann } \\
\text { secara berbeda dan terpisah antara } \\
\text { Pembeli dan Penjual }\end{array}$ & Sesuai & Berhasil \\
\hline 6 & $\begin{array}{l}\text { Form } \\
\text { pendaftaran } \\
\text { Penjual dan } \\
\text { Pembeli }\end{array}$ & $\begin{array}{l}\text { Mengisikan data } \\
\text { tidak lengkap }\end{array}$ & $\begin{array}{l}\text { Muncul peringatan pada field } \\
\text { yang kosong dan diminta untuk } \\
\text { diisi }\end{array}$ & Sesuai & Berhasil \\
\hline
\end{tabular}

\section{KESIMPULAN}

Dari hasil penelitian dapat di simpulkan bahwa dengan barang yang sering laku terjual maka barang tersebut akan selalu ditawarkan kepada pelanggan sehingga dapat menarik minat sang pembeli untuk membelinya. Adanya aplikasi web Bento Sport yang telah tersedia proses transaksi antara penjual dan pembeli dapat berjalan mudah. Pemilik Toko dapat mengecek kersediaan atau sisa barang yang telah dijualnya yang telah didaftarkan pada aplikasi. Pada aplikasi ini pemilik dapat mengecek perkembangan usahanya pada tab laporan penjual yang telah 
Journal of Computer System and Informatics (JoSYC)

Volume 2, No. 4, August 2021, Page 316-320

ISSN 2714-8912 (media online)

ISSN 2714-7150 (media cetak)

DOI 10.47065/josyc.v2i4.849

tersedia yang dapat di akses melalui login sebagai pemilik Toko atau Penjual. Pelanggan atau calon pembeli langsung di suguhkan daftar barang yang dijual meliputi barang terlaris maupun barang baru yang telah didaftarkan oleh sang penjual dan dapat mengetahui ketersediaan barang melalui detail barang.

\section{REFERENCES}

[1] B. H. Purnomo, 'METODE DAN TEKNIK PENGUMPULAN DATA DALAM PENELITIAN TINDAKAN KELAS (CLASSROOM ACTION RESEARCH)', p. 6.

[2] T. S. Jaya, 'Pengujian Aplikasi dengan Metode Blackbox Testing Boundary Value Analysis', Jurnal Informatika, p. 4, 2018.

[3] F. Purwaningtias, 'Penerapan Product Knowledge dan Strategi UpSelling Pada Chandra Tech Palembang', jpit, vol. 3, no. 2, pp. 253 258, May 2018, doi: 10.30591/jpit.v3i2.826.

[4] T. A. Cinderatama and A. F. Dianta, 'Aplikasi e-Marketplace untuk Penjualan Ikan Cupang Berbasis Web', vol. 2, no. 2, p. 6, 2018

[5] D. T. Hernandhi, E. S. Astuti, and S. Priambada, 'DESAIN SISTEM INFORMASI PEMASARAN BERBASIS WEBSITE UNTUK PROMOSI (Studi Kasus pada Kedai Ayam Geprak \& Sambal Bawang Malang)’, p. 10. 